\title{
BMJ Open Qualitative study to explore what patients with heart failure find significant during integrated palliative care sessions in a Danish clinic
}

Stine Gundtoft Roikjær (D) , , ${ }^{1,3}$ Charlotte Paaske Simonÿ, ${ }^{4,5}$ Helle Ussing Timm ${ }^{1,3}$

To cite: Roikjær SG, Simonÿ CP, Timm HU. Qualitative study to explore what patients with heart failure find significant during integrated palliative care sessions in a Danish clinic. BMJ Open 2020;10:e043955. doi:10.1136/ bmjopen-2020-043955

- Prepublication history for this paper is available online. To view these files, please visit the journal online (http://dx.doi. org/10.1136/bmjopen-2020043955).

Received 19 August 2020 Revised 11 December 2020 Accepted 18 December 2020

Check for updates

(C) Author(s) (or their employer(s)) 2021. Re-use permitted under CC BY-NC. No commercial re-use. See rights and permissions. Published by BMJ.

${ }^{1}$ Institute of Clinical Research, University of Southern Denmark, Odense, Denmark

${ }^{2}$ Medicine 2 Cardiology, Næstved, Slagelse and Ringsted Hospitals, Region Zealand, Denmark

${ }^{3}$ REHPA, Knowledge Center for Rehabilitation and Palliative Care, Nyborg, Denmark

${ }^{4}$ Institute for Public Health, University of Aarhus, Aarhus, Denmark

${ }^{5}$ Department of Research, Næstved, Slagelse and Ringsted Hospitals, Region Zealand, Denmark

Correspondence to Dr Stine Gundtoft Roikjær; stine.roikjaer@gmail.com

\section{ABSTRACT}

Objective In the field of palliative care (PC) as it is integrated into heart failure (HF) treatment, it is essential to explore the patient experience and build on this knowledge for the further development of PC practice and policy. Based on an intervention study, this paper explores what patients with HF find significant in integrated sessions using a narrative S' approach.

Design We conducted a semistructured interview study with a qualitative analysis focused on meaning making. The study follows the guidelines of Consolidated Criteria for Reporting Qualitative Research.

Participants and setting The inclusion criteria for the PC intervention were (1) a new diagnosis of HF, (2) follow-up treatment at this local Danish HF clinic and (3) informed consent to participate in the integrated PC intervention. The only exclusion criterion was if the patient was already engaged in a PC programme. 20 patients agreed to participate in the intervention, and 12 of these completed the S' approach sessions and participated in this interview study.

Results Overall, the analysis showed that the integrated S' approach sessions were successful in joining an embodied patient perspective with a medical perspective. The thematic analysis resulted in three themes supporting the overall findings: sessions bring comfort, telling your story provides a sense of meaningfulness, and integrating perspectives of HF into everyday life.

Conclusion The method using the S' approach in integrated PC and HF sessions was significant in various ways. First, patients experienced a calm and safe atmosphere and perceived that the nurse was truly interested in them. Second, the integrated sessions based on the S' approach were able to bring comfort to lived physical, psychosocial and existential issues. Last, it allowed patients to combine their embodied understanding of HF with a medical perspective, thereby finding meaning in the sense of how everything is connected.

\section{INTRODUCTION}

There is a broad clinical consensus that palliative care (PC) should be an essential part of the treatment and care of patients with heart failure (HF). ${ }^{12}$ Nevertheless, there is a gap in our knowledge regarding integrated $\mathrm{PC}$ in HF treatment from diagnosis onwards.
Strengths and limitations of this study

Qualitative interviews provided insight into the essential patient experience.

- Our recruitment strategy had to be altered due to lack of inclusion.

- Patients in this interview study were all ethnic Danes and predominantly male.

- Limitations of generalisability are common to qualitative research methodologies.

Specifically, the current research literature lacks insight into the significance of integrated PC for patients with $\mathrm{HF}$.

The patient perspective in healthcare is a foundation for a democratic and patientcentred care approach. ${ }^{34}$ Hence, knowledge of the patient experience is essential for the further development of meaningful and integrated PC in HF treatment. This article describes the experiences of patients participating in a PC intervention with a narrative approach.

\section{The scope of HF}

HF affects over 37000000 people worldwide, making it a serious global health problem in need of widespread concern and attention. ${ }^{5}$ Cardiology is a highly evidence-based medical area focused on saving lives by solving structural or biomedical problems of the heart. Advances in technology and pharmaceuticals have had a positive effect on cardiovascular death. ${ }^{6}$ Nevertheless, with regard to chronic $\mathrm{HF}$, the main option is slowing the progression of the illness and treating the accompanying symptoms.

Living with $\mathrm{HF}$ has been described as a roller coaster you cannot get off ${ }^{7}$ or as a Sisyphean struggle. ${ }^{8}$ Both descriptions capture the experience of an unreliable illness that fluctuates from periods of deterioration with life-threatening events to better times 
where symptoms are under control. In addition, studies have shown that patients with HF have difficulty understanding their condition, possibly increasing the risk of acute events. ${ }^{910}$

\section{Different perspectives on $\mathrm{PC}$ and $\mathrm{HF}$}

PC is defined as using a holistic approach to increase quality of life for people suffering from life-threatening illnesses by relieving problems of a physical, psychosocial and existential nature. ${ }^{11}$ Embedded in the philosophy of PC is an acknowledgement of the essential embodied patient perspective. ${ }^{12}$

The medical anthropologist and MD Arthur Kleinman has argued for the importance of patient perspective within his theory on illness and disease. He contends that the embodied illness perspective is essential in the holistic treatment and care of patients with chronic diagnoses. ${ }^{4}$ The illness perspective holds the key to a comprehensive understanding of living with HF, as it is the "principal difficulties that symptoms and disability create in our life' (p4). ${ }^{4}$ The nature of illness as an embodied and subjective experience requires a narrative and explorative approach. Conversely, a medical professional's disease perspective may be based on a biomedical view of a problem formed by years of medical training. ${ }^{4}$ Hence, to provide holistic PC, a method that incorporates several different perspectives is needed.

Ideally, PC should be implemented alongside standard treatment of HF. However, the current research literature $^{126}$ focuses on medical and technological strategies in the advanced stages of HF. More research on the existential aspects of $\mathrm{HF}$ is needed.

\section{Exploring the patient experience}

In recent decades, healthcare and research have developed a more democratic and patient-centred focus, recognising the importance of the patient's perspective. ${ }^{313}$ Although the reasons might seem obvious to our reader, we will try to articulate a few.

In general, health research seeks to add value and quality to health interventions. ${ }^{14}$ Incorporating evidence of real-life experiences into both research and healthcare is seen as an essential part of improving patient outcomes and ensuring positive experiences of healthcare. ${ }^{14}$ This is supported by a recent systematic review ${ }^{15}$ indicating a positive association between patient experience, clinical effectiveness and patient safety.

In the new field of general PC as it is integrated with HF treatment, it is essential to explore the patient experience and build on this knowledge in the further development of practice and policy. Narrative inquiry can provide insight into how a subject experiences an intervention. In addition, narratives can be used as an intervention itself.

\section{The narrative S' approach}

Narratives in research or practice are not new. Sociologist Arthur Frank argued that illness always calls for a story, ${ }^{16}$ and a narrative can provide a meaningful understanding of experiences, events or ideas. Interventions using personal narratives have shown promise with existential distress in PC. ${ }^{17-19}$ However, it is not easy to apply the resource-intensive reminiscence-based narrative in the fast-moving hospital setting. ${ }^{17-19}$

The S' approach ${ }^{20}$ was developed by Ternestedt and her team to operationalise PC in a clinical setting by exploring needs and resources in the dimensions of symptom control, self-image, self-determination, social relationships, strategy for the future and sense of coherence. ${ }^{2021}$ Based on the idea of narratives as a method to provide meaningful patterns, the $S^{\prime}$ approach aims to integrate patient and professional perspectives in $\mathrm{PC}^{21}$ However, the literature lacks research on the S' approach in general hospital PC and in HF treatment.

\section{METHODS}

\section{Aim}

This study explored what patients with HF found significant in integrated PC and HF sessions using a narrative approach.

\section{A PC intervention for HF}

On the basis of current research ${ }^{17}$ exploring the need for $^{8}$ and lack of knowledge of PC in a general hospital setting, an intervention was designed and implemented alongside the standard treatment provided by a general outpatient HF clinic at a hospital in Denmark.

The principal ideas for this PC intervention were (1) to operationalise the WHO definition of PC, (2) to integrate patient and professional perspectives using dialogue and personal narratives and (3) to integrate the PC intervention into the standard treatment and care of patients with HF to enable large-scale implementation.

These ideas were converted into the following actions: educating the interdisciplinary team in PC as well as HF through a seminar. The seminar presented current knowledge on PC for patients with HF, examples of the organisation of PC in HF treatment in Denmark and a panel discussion on clinical cases. Furthermore, the intervention nurses were trained in communication with a narrative S' approach. Through workshops, the interdisciplinary project group adjusted the inspirational S' questions to focus less on end of life and more on life with a life-threatening illness.

The intervention nurses were responsible for exploring the patient perspective using the adjusted S' approach. They invited the patients to share experiences, worries or thoughts from their life supported by a guide with inspirational questions. The narrative approach was integrated into the standard HF sessions, and the nurses documented the narrative under $S$ categories in the patient's file, making it accessible to the interdisciplinary team. Every 4 weeks, an interdisciplinary conference was held. During the conference, the nurses presented possible PC needs based on the $S^{\prime}$ words and received recommendations from the other members on how to manage a need. 


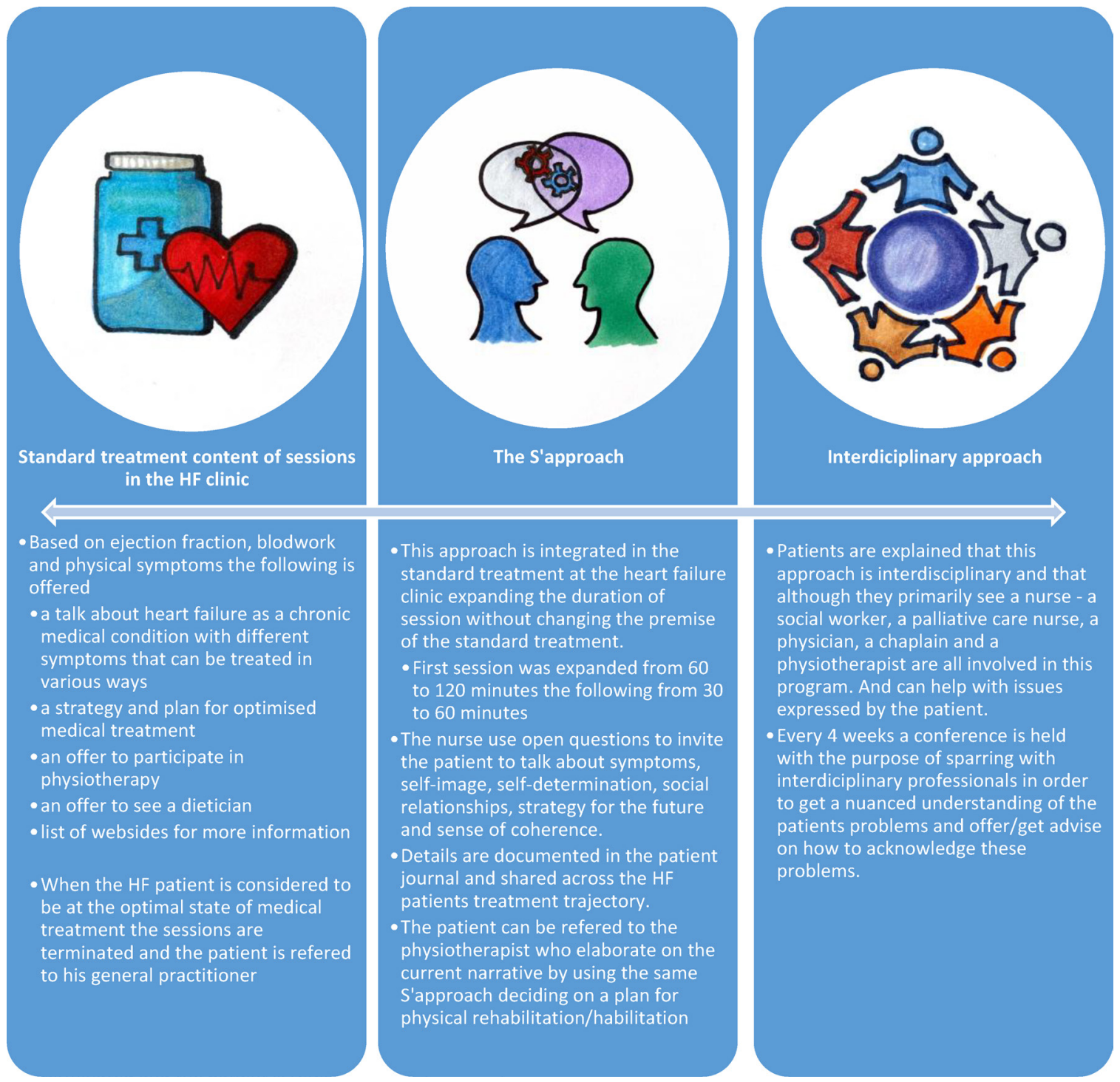

Figure 1 Integrated heart failure (HF) and palliative care (PC) intervention.

The mean number of sessions with the nurse was 8 , with a range from 3 to 13 . Figure 1 illustrates the integrated intervention.

\section{Patient and public involvement}

As this is a qualitative interview study, patients played an essential part as informants. In addition, this study is part of a larger PhD study aimed at changing clinical practice. During this process, patients and professionals from cardiology and PC were involved at different stages: (1) we conducted semistructured interviews with patients with HF to inform needs for a PC intervention; (2) we conducted workshops with professionals to develop integrated PC and HF sessions using a narrative approach.

\section{Study design}

We chose a qualitative interview study design to explore subjective experience of patients with HF of sessions using the $\mathrm{S}^{\prime}$ approach (hereafter, these are referred to as 'sessions'). The study follows the Consolidated Criteria for Reporting Qualitative Research guidelines. ${ }^{22}$

\section{Participants}

The inclusion criteria for the PC intervention were (1) a new diagnosis of HF, (2) follow-up treatment at this local Danish HF clinic and (3) informed consent to participate in the integrated PC intervention. The only exclusion criterion was if the patient had already followed a PC offer due to other illnesses. The inclusion period was March-August 2019, and the aim was to include between 20 and 25 participants. As patients were referred to the HF clinic, the first author approached them by phone or in person, inviting them to join the integrated PC intervention. Patients all received information about the study in writing and were encouraged to discuss it with family, professionals or the first author before deciding to participate. In all, 22 patients were approached, 20 agreed to participate in the PC intervention and 12 of these completed the sessions and participated in this interview study (see figure 2).

\section{Data collection}

To gain an understanding of the lived experiences of participating in the sessions, the first author planned 


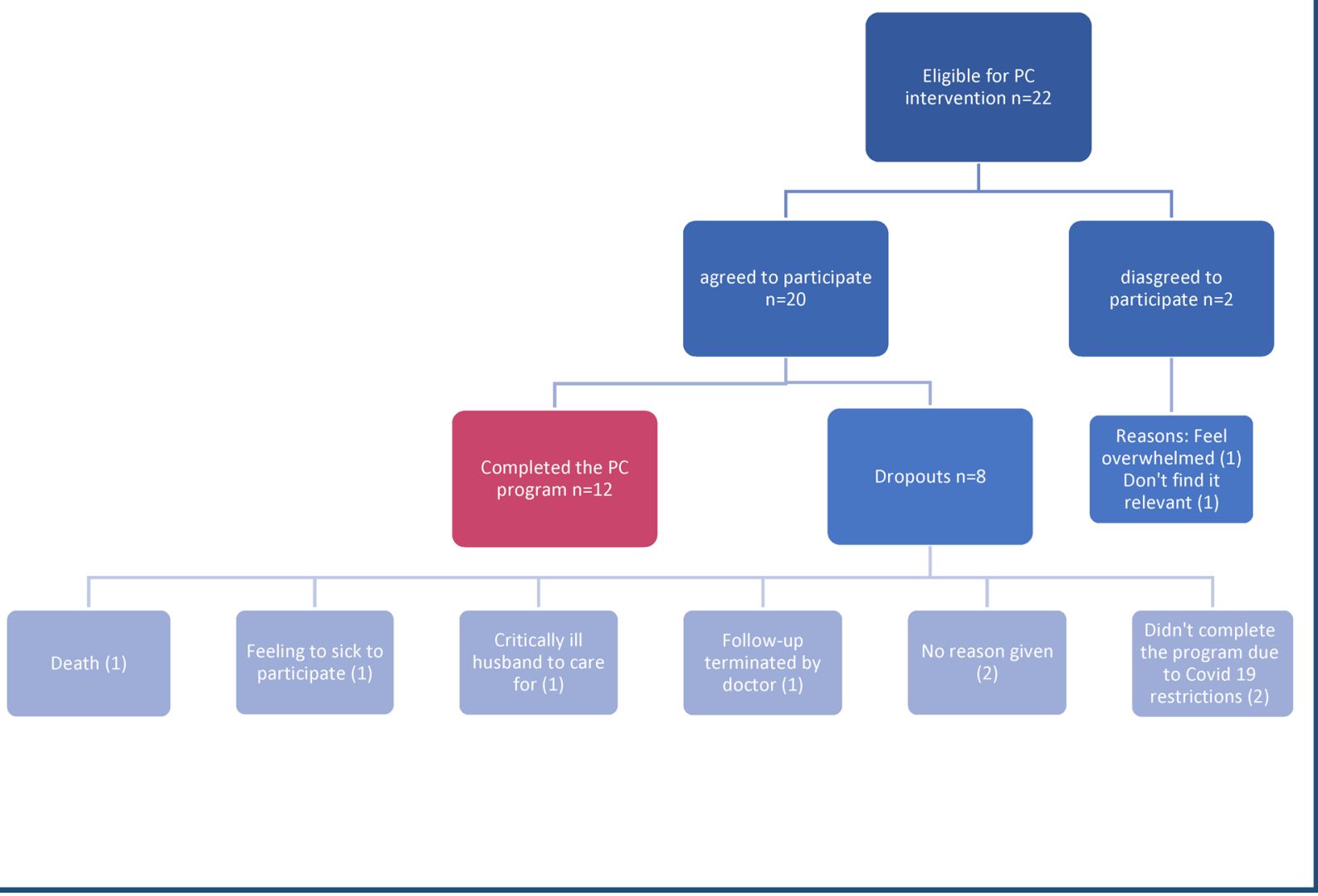

Figure 2 Flow chart of participants. PC, palliative care.

and performed individual semistructured interviews with the patients as they concluded the sessions. Participant observations were conducted by the first author during earlier sessions; hence, a relationship had already been established with the patients. Only the interview data will be presented in this analysis.

The key question, 'please tell me your experiences with the sessions at the HF clinic', guided the interview. If necessary, the first author followed up with, 'can you say a bit more about that?' or 'what did that mean to you?'

To create a calm and engaged atmosphere as well as a sense of neutrality, most interviews were conducted at the participants' homes. Some participants preferred to have their spouse present. However, due to logistics, three patients preferred that the interview took place at the HF clinic in conjunction with their last follow-up visit. The interviews had a mean duration of $61 \mathrm{~min}$ and were audio recorded and transcribed ad verbatim. By the 10th interview, data saturation consistent with our aim, sampling plan and inclusion criteria had occurred. ${ }^{23}$

Demographic data for the patients participating in the study are presented in table 1 .

\section{Data analysis and interpretation}

The first author used the software programme NVivo V.12 Pro for coding and managing data, with the following steps as described by Green: (1) organising the data, (2) familiarising ourselves with the data, (3) coding the data

\begin{tabular}{|c|c|c|c|c|c|c|c|c|c|c|c|c|}
\hline Participant & P1 & P2 & P3 & P4 & P5 & P6 & P7 & P8 & P9 & P10 & P11 & P12 \\
\hline Sex & $\mathrm{F}$ & M & $\mathrm{F}$ & M & M & $M$ & M & $\mathrm{F}$ & $\mathrm{F}$ & M & $\mathrm{M}$ & M \\
\hline Married/partner & Yes & No & No & Yes & Yes & Yes & Yes & No & No & Yes & Yes & Yes \\
\hline Other diagnoses & $\mathrm{Ml}$ & $\mathrm{VAB}, \mathrm{AF}$ & NST, COL & $\mathrm{BPH}$ & NST & SCA & ASHD & NP & ASHD, RI & & $\mathrm{CHD}$ & AF, HT \\
\hline
\end{tabular}

$\mathrm{AF}$, atrial fibrillation; ASHD, arteriosclerotic heart disease; $\mathrm{BPH}$, benign prostatic hyperplasia; $\mathrm{CHD}$, coronary heart disease; COL, chronic obstructive lung disease; HT, hypertension; MI, mitral insufficiency; NP, nephropathy; NST, non-ST-elevation acute myocardial infarction; RI, renal insufficiency; SCA, sudden cardiac arrest; VAB, bicuspid aortic valve. 
and (4) creating the themes. ${ }^{24}$ The qualitative thematic analysis, informed by Kvale and Brinkmann, focused on meaning making. ${ }^{25}$ It was derived through a continuous hermeneutic process of going back and forth between parts and the whole in discussion with the coauthors. ${ }^{25}$ The analysis was further interpreted using theory and additional research from the field.

\section{RESULTS}

Overall, the analysis showed that the integrated S' approach sessions were successful in joining patient and professional perspectives. This approach was meaningful for the patient in terms of integrating illness into everyday life.

For many patients, their HF diagnosis manifested as physical symptoms, anxiety and worries in their everyday life. The sessions with a narrative approach provided an inviting, calm and safe atmosphere to express worries and share stories. This in turn led to a sense of coherence and meaningful understanding of HF and thereby provided comfort. Those who did not experience problems still appreciated the personal focus and atmosphere but were not able to express the significance of participating. The thematic analysis resulted in three themes that support the overall findings: sessions bring comfort, telling your story provides a sense of meaningfulness and integrating perspectives of heart failure into everyday life.

We present these themes supported by quotes from patients.

\section{Sessions bring comfort}

The patients perceived the integrated HF and PC sessions using the $S$ ' approach as a response to their problems. Most expressed that regardless of their nature, their problems were always welcomed and recognised.

Many patients highlighted issues of anxiety as a reaction to their diagnosis of HF. One described feeling a state of panic:

Well, I was panicking. Just as soon as I had fallen asleep, I woke up. I couldn't breath-and this had nothing to do with my illness. It was fear-pure and simple. P8

This anxiety kept the patient from socialising. She would turn down every invitation and stay home watching her newly planted beautiful flowers. Flowers, she told me during an earlier conversation, that she imagined would adorn her grave. She continued the interview by clarifying how the sessions relieved her from that state of panic, and the nurse helped her get a grip on reality and fear:

She (the nurse) made me feel in good hands. Well, just that fact, and the fact that she had everything under control, and me knowing that everything was as it should be and not as horrific as I thought. Because I thought I was about to die. P8
Another patient specifically articulated a transition between chaos before a session and a sense of calm after a session:

I am always completely relaxed after seeing Helen (fictive name for the nurse). Before I get there, I am in a state of oh oh (swirls her head around making frantic gestures with her arms). P9

An example of a response to an existential problem was the story told by P11. He described how his father died from a heart attack when he was only 56 years old. He speaks of the incident as 'tragic' and 'hectic'. As the following quote shows, he was very angry with his mother and blamed her for his father's death:

My father had died and my mother had found another... I didn't visit her for 12 years-I didn't. P11

He had talked to the nurse about this, and in addition to listening, she advised him to talk to the hospital chaplain because she suspected that this could be connected to his current anxiety. At first, he had declined, but after giving it some thought, he had a talk with the chaplain. I asked him what that meant to him talking to the nurse and the chaplain. He responded with a quote that conveyed a sense of comfort as well as togetherness:

I was sad-I really was. However, it feels good to talk. Had I been alone I think this problem would have become even bigger. P11

In terms of practical problems, the patients shared how the nurses offered constructive advice. One patient (P11) mentioned that he had trouble remembering taking his pills in the evening due to sporting activities. The nurse advised him simply to set an alarm on his phone, and now he remembers the pills.

It seems, however, that not all problems can be resolved as a patient with chronic insomnia pointed out.

I have spoken with her (the nurse) about it, but unfortunately, I am none the wiser. P7

He wished that the programme had involved some joint interdisciplinary sessions to tackle this problem. However, he continued:

You can discuss how to organise this, but I have been in the hands of competent people, and that has brought me comfort. P7

Even if the patients did not experience psychosocial, existential or practical problems, all expressed great satisfaction with the sessions. Many stated that this should be offered to everyone, regardless of diagnosis. They especially highlighted the atmosphere and attentiveness projected during the sessions:

There you feel that you are the only one in the world they are concerned about. P5

In summary, the analysis shows how patients felt cared about, which enabled them to share their personal 
experiences, thoughts or worries. The nurses appeared willing to address any issue, and patients perceived them as competent and concerned. The patients articulated how they felt a sense of comfort after sessions.

\section{Telling your story provides a sense of meaningfulness}

The S' approach builds on dialogue and narratives, and this was appreciated by patients:

It is a nice feeling-especially as a patient-that you know that someone wants to hear what you have to say. P9

The interview data showed how patients interpreted this as genuine interest from the professionals. Many spoke of this as a new experience compared with other times they or loved ones had needed support during illness as the following quote supports:

I will say-I felt someone took care of me. It was different when I came home after having the blood clot—no one took care of me then. P11

The patients described telling stories of difficulties coping with, for example, the loss of a father, a complicated relationship in the family, or more obvious illnessrelated stories of prior illnesses, hospitalisations and fear of dying.

The opportunity to share and tell stories brought about a sense of meaningfulness and coherence for most patients. One patient (P7) described that the approach took into account that he is a whole person and not only the part with illness. Another reason was that by sharing from his everyday life (P11), the nurse was able to obtain a more nuanced picture of his problems and was, therefore, better able to support him. Complementary, another reported that he himself had benefited from an improved understanding of the whole situation:

It is significantly meaningful, both in regards to medicine and that stuff but also in how one understands... how should I put it... the whole thing. P4

The following example further supports how this approach was seemingly meaningful and brought a sense of how everything is connected to the patients: one patient (P5) explained during the interview that he quite quickly felt physically back in shape. Nevertheless, he had trouble concentrating and felt easily overwhelmed, which resulted in a bad mood. He had taken this up during sessions, believing that the pills were the reason for his mental state. The nurse listened to his troubles and agreed to adjust some of the medication. However, she had asked him to talk more about his situation at home. Encouraged by the nurse's invitation, this made him share the story of his daughter who was going through an awful divorce, which affected the whole family. He worried about her and the granddaughter. The daughter, on the other hand, was worried that she had caused the hospitalisation of her father. During the interview, he related how as he told his story to the nurse, he came to realise that this might indeed be a factor in his mental state and expressed gratitude that the sessions allowed for such reflections.

Another example of feeling a sense of coherence is one of inheritance and reminiscence. A patient told me stories of how she had inherited personal items from her grandparents, and now she had passed them on to her children and grandchildren.

you know what; I will give it to you now. I have no room for it, and this way I can enjoy seeing you use it. P9

She expressed how this in part was brought on by the sessions and the stories she shared with her nurse.

These examples show how telling stories from lived life can help recognise the bigger picture, thereby creating a sense of meaning and coherence. However, not all patients exploited this opportunity to share stories and narratives. One explained that she would rather talk to loved ones if she experienced feeling sad or anxiety and denied a need to do so. She stated that it was a personality trait:

I'm not really one for company or talk. P3

Another explained that he had no reason to share:

Well, I don't feel we have any problems-or that I have. And the things you mention about sharing different things, I just don't think there is a reason to. P12

Both of these patients perceived their life to be no different now from before the diagnosis, as they had no problems of either a physical or an existential nature. However, when I asked one of the patients if she found the nurses questions provocative, she denied this. I sensed that the nurse was sensitive to the patient's perspective and refrained from pushing for a story. Forcing these patients to share stories from their everyday life would have been meaningless to them.

\section{Integrating perspectives of HF into everyday life}

Some patients expressed a need to comprehend the physiology in terms of their diagnosis and their experienced symptoms. Others had a need to understand the connection between their blood tests and treatment or if there was anything they could do in their everyday lives to improve their outcomes. Most conveyed a need to know what the HF diagnosis would mean for their everyday life and future.

These needs share an underlying wish to join a personal and embodied understanding of $\mathrm{HF}$ with a medical perspective.

Discussions of the severity of $\mathrm{HF}$ and considerations of death were included in the sessions. The patients shared that they welcomed the talk of death and dying:

Well, it is the one thing you can be certain of in this life. P4 
This patient found death to be a natural part of life and elaborated on how he and his family had always spoken openly about their wishes in terms of death. However, he went on to express what I interpret as a difference between preparing for death and being prepared to die:

\section{it's like... You can never be prepared 100\%. P4}

Another patient (P11) told me that due to the sessions, he had written his will. He had been visiting churches in his parish, as he wanted to hear the priest's sermons and choose a burial site. In addition, another spoke about how he had gone over legal documents, ensuring that everything was up to date in case of his death. He believed that this was just as important as deciding on the funeral:

It brings me comfort that my family is financially secure in case I die-to know that my bereaved are comfortable and won't need that struggle on top of everything else. P6

I asked him what it meant for him to be able to talk these things over with the nurse, and he elaborated on finding a balance between fear of dying due to the seriousness of the illness and letting go:

I give it less and less attention-I mean it has to get some consideration-you can never let it go completely. It is present but it must not dominate (life). P6

All patients let me understand that death was probably not in their imminent future, as they felt better after treatment and the sessions. This sense of feeling better was not restricted to physical well-being but just as significantly a psychological well-being. One patient put it this way:

If the kids asked how I was, I cried excessively and instantly. Now when they ask, I tell them that I am brilliant and they are so happy. P8

She went on to tell me that the sessions had given her hope and a way to integrate her worries of HF within her everyday life:

It's like Winnie the Pooh is saying 'the rest of the days you have to live' and that is so true. P8

As a whole, these examples show that sessions supported the patients in combining their embodied understanding of HF with a medical perspective. Therefore, the sessions helped patients integrate different perspectives of $\mathrm{HF}$ in their everyday life. The patients considered death a threat avoided for now due to the treatment. However, they recognised the severity of the illness and felt supported in balancing worries with hope and living life.

\section{DISCUSSION}

PC is a holistic approach focusing on relieving physical, psychosocial and existential problems. ${ }^{11}$ Based on the analysis, we found overall satisfaction with the integrated PC sessions using an S' approach. The patients described a calm and inviting atmosphere with time for them to share stories from their life. They felt a genuine concern from the nurse and understood the sessions as a response to their problems, regardless of their nature. Furthermore, we found that most patients in our sample felt that the sessions provided relief for their problems.

This is supported in an RCT study on the effects of the $\mathrm{S}^{\prime}$ approach as integrated PC. ${ }^{26}$ Brännström and Boman found that integrated care relieved physical, physiological, social and spiritual problems. Furthermore, it reduced the number of hospitalisations and the number of days spent in the hospital. ${ }^{26}$ However, that study differed from our current study in several ways. In addition to the obvious differences in methodology, the patients in the RCT study were suffering from advanced HF, and the intervention was home based. To our knowledge, our study is the first to involve participants in an intervention at the time of diagnosis.

PC is often mistakenly seen as exclusively an end-of-life intervention delivered only by specialists. However, as our study shows, patients were able to convey and relieve problems of varying natures even though they were in the early stages of their illness and in a general HF clinic. The early onset of problems as well as the variety of needs over the course of the illness has been found in similar studies, ${ }^{27} 28$ which strengthens the argument for integrated PC. However, our study found that not everyone experiences psychosocial or existential problems in the early stages of HF. Screening for psychosocial and existential problems as triggers for PC could be helpful in the organisation of PC for patients with HF.

The outcomes related to the comfort that the patients described have also been reported before. A phenomenological study ${ }^{29}$ with the aim of describing comfort and discomfort experienced by inpatients at a PC unit concluded that PC units created a space of comfort where the patient could find a suitable therapeutic response to their needs. ${ }^{29}$ Based on our findings, we would argue that the key to comfort is not whether the setting is general or specialised, but rather that there is a holistic approach embedded in the philosophy of PC that acknowledges all problems presented by patients. Nevertheless, not all problems could be solved during the sessions.

Several studies have shown that patients find it hard to comprehend the nature of $\mathrm{HF}^{8-10}$ The PC sessions using the S' approach that integrates patient and professional perspectives on illness and disease proved valuable to the patients in terms of understanding HF. Kleimann has argued that illness perspectives are formed from how patients understand and talk about symptoms, how the disease is viewed in our culture and, most importantly, the patient's individual life world. ${ }^{4}$ Our analysis shows that when patients experience a nurse acknowledging their life stories, it facilitates internal reflection. This supports patients in achieving a sense of how everything is connected, which again enables a nuanced understanding of HF. This outcome could mean a decrease in unnecessary acute events, as Brännström and Boman found. ${ }^{26}$ 
The current organisation in HF clinics does not prioritise acknowledgement of such stories. At present, the main purpose is to adjust medical treatment to clinical symptoms and known effects. Our study showed that providing time and creating a safe atmosphere to share stories and incorporate the patient perspective had a significantly meaningful impact on patients. However, to change current practices and policies, there might be a need to strengthen arguments through cost-benefit analyses and clinical trials.

\section{Limitations}

To obtain a representative sample, the strategy was to invite patients as they were referred to the HF clinic. This strategy failed as patients in the hospital ward were not detected. We had to change our strategy and manually go through referral lists. This is a clear limitation, as patients eligible for participation were not invited.

Another limitation in this interview study is that participants were all ethnic Danes and predominantly male. This is a problem, as a recent cohort study ${ }^{30}$ showed a higher incidence of heart diseases among non-Western immigrants than among Danish-born patients. To achieve a more nuanced picture of the significance of integrated PC in HF treatment, further research could target these non-Western immigrant populations.

\section{CONCLUSION}

The method using the S' approach in integrated PC and HF sessions was shown to be significant in various ways. First, it allowed the patients to feel and experience a calm and safe atmosphere with a nurse who was truly interested in them. Second, integrated sessions based on the S' approach brought comfort to participants experiencing lived physical, psychosocial and existential issues. Last, it allowed patients to combine their embodied understanding of HF with a medical perspective, thereby finding meaning in the sense of how everything is connected. These findings are in agreement with the aim of $\mathrm{PC}$ and provide a 'real-life' argument for an integrated approach to PC in HF treatment.

These findings might reflect a common sense interpretation to the reader. However, the discussion of the findings in the context of a theoretical framework and with additional research provides a more general reflection. This reflection is vital for future integrated PC.

\section{Ethical approval and consent to participate}

The Committee on Health Research Ethics for Region Zealand, Denmark (REG-108-2017), covering Næstved, Slagelse and Ringsted Hospitals, approved this study. Further ethical considerations for this project were based on both the International Council of Nurses ethical guidelines ${ }^{31}$ and the Helsinki Declaration. ${ }^{32}$ The patients were made aware that this study was part of a PhD study.

Correction notice This article has been corrected since it first published. The provenance and peer review statement has been included.

\section{Twitter Stine Gundtoft Roikjær @RoikjR}

Acknowledgements The authors would like to thank the patients for sharing their experience with this PC intervention. Furthermore, they are thankful that the HF clinic found the study to be worthy of investing their time and resources.

Contributors All authors were involved in designing the study to meet the objective. SGR executed the study, collected data, coded, analysed and interpreted the data as well as drafted and revised the manuscript. CPS contributed by revising the intellectual content of the manuscript. HUT contributed in both analysis and in revising the intellectual content of the manuscript.

Funding This study was funded under a larger PhD grant from the Næstved, Slagelse and Ringsted Hospitals' Research Fund. Grant number is not applicable.

Competing interests None declared.

Patient and public involvement Patients and/or the public were involved in the design, or conduct, or reporting, or dissemination plans of this research. Refer to the Methods section for further details.

Patient consent for publication All participants stated their consent for publication as part of their consent to participate.

Provenance and peer review Not commissioned; externally peer reviewed.

Data availability statement Data are available upon reasonable request. The qualitative dataset generated and analysed during this study are available from the first author but restrictions apply to the availability of these data.

Open access This is an open access article distributed in accordance with the Creative Commons Attribution Non Commercial (CC BY-NC 4.0) license, which permits others to distribute, remix, adapt, build upon this work non-commercially, and license their derivative works on different terms, provided the original work is properly cited, appropriate credit is given, any changes made indicated, and the use is non-commercial. See: http://creativecommons.org/licenses/by-nc/4.0/.

Author note SGR is a PhD student, has an MSc in public health and is also a registered nurse with cardiac experience. At the time of this study, she was a PhD student. CS is the head of research at Næstved, Slagelse and Ringsted hospitals. HT is a professor in palliative care and at that time employed at REHPA, the Knowledge Center for Rehabilitation and Palliative Care.

ORCID iD

Stine Gundtoft Roikjær http://orcid.org/0000-0002-5851-7577

\section{REFERENCES}

1 Hansen VB, Aagaard S, Hygum A. The first steps taken to implement palliative care in advanced heart disease: a position statement from Denmark. J Palliat Med 2020:1-8.

2 Shah AB, Morrissey RP, Baraghoush A, et al. Failing the failing heart: a review of palliative care in heart failure. Rev Cardiovasc Med 2013;14:41-8.

3 Thorgaard K, Jensen UJ. Evidence and the end of medicine. Med Health Care Philos 2011;14:273-80.

4 Kleinman A. The illness narratives - suffering, healing \& the human condition. Basic Books. New York: Perseus Books Group, 1988.

5 Ziaeian B, Fonarow GC. Epidemiology and aetiology of heart failure. Nat Rev Cardiol 2016;13:368-78.

6 Kandaswamy E, Zuo L. Recent advances in treatment of coronary artery disease: role of science and technology. Int J Mol Sci 2018;19. doi:10.3390/ijms19020424. [Epub ahead of print: 31 Jan 2018].

7 Brännström M, Ekman I, Boman K, et al. Narratives of a man with severe chronic heart failure and his wife in palliative advanced home care over a 4.5-year period. Contemp Nurse 2007;27:10-22.

8 Roikjær SG. Når hjertet svigter - patientperspektiver og basa palliativ indsats på hospitalet. (When the heart fails - patient perspectives and general palliative care at the hospital). Omsorg 2020;4:40-44.

9 Boyd KJ, Murray SA, Kendall M, et al. Living with advanced heart failure: a prospective, community based study of patients and their carers. Eur J Heart Fail 2004;6:585-91.

10 Horowitz CR, Rein SB, Leventhal H. A story of maladies, misconceptions and mishaps: effective management of heart failure. Soc Sci Med 2004;58:631-43.

11 World health organization. WHO definition of palliative care, 2002. Available: https://www.who.int/cancer/palliative/definition/en/

12 Addington-Hall JM, Higginson IJ. Introduction. In: Addington-Hall JM, Higginson IJ, eds. Palliative care for non-cancer patients. Oxford: Oxford University Press, 2006: 1-11. 
13 Sacristán JA, Aguarón A, Avendaño-Solá C, et al. Patient involvement in clinical research: why, when, and how. Patient Prefer Adherence 2016;10:631-40.

14 Siriwardena AN, Gillam S. Quality improvement science different perspectives on quality. Qual Improv Sci2013:123-30.

15 Doyle C, Lennox L, Bell D. A systematic review of evidence on the links between patient experience and clinical safety and effectiveness. BMJ Open 2013;3:e001570.

16 Frank AW. The capacities of stories. In: letting stories breathe - a socio-narratology. Chicago and London: The University of Chicago Press, Chicago and London, 2012: 20-44.

17 Roikjær SG, Missel M, Bergenholtz HM, et al. The use of personal narratives in hospital-based palliative care interventions: an integrative literature review. Palliat Med 2019;33:1255-71.

18 Kwan CWM, Ng MSN, Chan CWH. The use of life review to enhance spiritual well-being in patients with terminal illnesses: an integrative review. J Clin Nurs 2017;26:4201-11.

19 Bentley B, O'Connor M, Shaw J. A narrative review of dignity therapy research. Aust Psychol 2017;52:354-62.

20 Ternestedt B-M, Andershed B, Eriksson M, et al. A good death. Journal of Hospice \& Palliative Nursing 2002;4:153-60.

21 Venborg A. S-tilgangen i palliation - hvad, hvorfor og hvordan? (The S' approach in palliation - what, why and how? Copenhagen, Denmark: Books on Demand GmbH, 2016.

22 Tong A, Sainsbury P, Craig J. Consolidated criteria for reporting qualitative research (COREQ): a 32-item checklist for interviews and focus groups. Int J Qual Health Care 2007;19:349-57.

23 Moser A, Korstjens I. Series: practical guidance to qualitative research. Part 3: sampling, data collection and analysis. Eur J Gen Pract 2018;24:9-18.
24 Green J. Analysing qualitative data. In: Green J, Browne J, eds. Principles of social research. New York: Open University Press McGraw-Hill Education, England, 2009: 75-89.

25 Kvale S, Brinkmann S. Interviewanalyser med fokus på mening (Interview analysis with focus on meaning). In: Interview. Det kvalitative forskningsinterview som håndværk (Interview. The qualitative interview as a craft). Copenhagen, Denmark: Hans Reitzels Forlag, 2015: 267-85.

26 Brännström M, Boman K. Effects of person-centred and integrated chronic heart failure and palliative home care. prefer: a randomized controlled study. Eur J Heart Fail 2014;16:1142-51.

27 Beernaert K, Deliens L, De Vleminck A, et al. Is there a need for early palliative care in patients with life-limiting illnesses? interview study with patients about experienced care needs from diagnosis onward. Am J Hosp Palliat Care 2016;33:489-97.

28 LaDonna KA, Bates J, Tait GR, et al. 'Who is on your health-care team?' asking individuals with heart failure about care team membership and roles. Health Expect 2017;20:198-210.

29 Coelho A, Parola V, Escobar-Bravo M, et al. Comfort experience in palliative care: a phenomenological study. BMC Palliat Care 2016;15:1-8.

30 Bo A, Zinckernagel L, Krasnik A, et al. Coronary heart disease incidence among non-Western immigrants compared to Danish-born people: effect of country of birth, migrant status, and income. Eur $J$ Prev Cardiol 2015;22:1281-9.

31 International Counsil of Nurses. The ICN code of ethics for nurses, 2012. Available: https://www.icn.ch/sites/default/files/inline-files/ 2012_ICN_Codeofethicsfornurses_\%20eng.pdf

32 World Medical Association. World Medical Association Declaration of Helsinki. Bull world Heal Organ 2001;79:373-4. 